\title{
Los incendios forestales
}

\author{
Pedro Montserrat Recoder
}

$\mathrm{H}$ emos vivido un drama este verano por el devastador incendio entre Riglos y Pantano de la PeñaLoarre, en bosques próximos a los pueblos y pardinas. Mantener tanta planta inflamable, guardar tanta leña con resina y hojarasca resulta peligroso y más ahora con el hombre actual que ya no vive del monte y gasta mucho "desde lejos" para detener lo imparable cuando sopla un viento fuerte. Es preferible la previsión y conviene dar ideas "de abuelo" que acaso sean útiles.

Nuestros antepasados vivían una pobreza digna y usaban a fondo sus recursos naturales, cortando leña o ramoneando el matorral con las cabras de los vecinos, con su dula que mantenia la prole familar y así unía los vecinos a su propiedad comunal. Ahora no se hace leña ni hay cabras en la sarda: creamos unos bosques bellos pero son frágiles y además descuidamos la propiedad común. Eso es grave y conviene aportar algo, ahora, de la experiencia en pastos del norte peninsular.

\section{EL PASIEGO BURGALES}

He visto culturas rurales en especial las ganaderas que han perdurado y aún se aprecia su impronta en el paisaje. Si un martes visitáis Espinosa de los Monteros, podréis ver su Mercado ganadero hasta las once y después la Feria semanal con productos exóticos que acuden a dicha Feria porque hay clientes en Trueba, Lunada y La Sia, que los compran. Si miramos los prados y pastos veremos la importancia de su cultura gestora, con hierba tierna para el ternero que necesita proteína y un pasto casi espigado (rico en energía) para producir leche. La cultura pasiega encontró en su experiencia dilatada lo que han descubierto los investigadores nutrólogos hace muy poco. Como en cualquier cultura milenaria, los pasiegos descubrieron el uso eficaz de sus recursos y nos conviené ver cómo usaban el fuego contra el incendio catastrófico. Mejor dicho, eso se hizo hasta que les prohibieron sus "fueguitos" y ahora deben hacerlo a escondidas. Sabían incendiar su brezal en febrero-marzo, cuando se inicia el renuevo del pasto en suelo húmedo, casi helado; un viento suave y orientado dirigía el "incendio superficial" que caldea y estimula la vida edáfica fertilizando el pasto que pronto acumulará el "abono" antes de que la lluvia arrastre fertilidad y contamine los arroyos; el fuego quema pocas áreas, una superficie fusiforme (dirección del viento suave) que será cortafuego en años sucesivos. He visto incendiar brezos al lado de sus hayedos y sin peligro, porque aprendieron de los abuelos que sacaban la miel del brezo renovado y muy florido.

\section{RESPONSABILIDAD}

Debe ser de todos, porque peligran vida y hacienda, pero además el incendio catastrófico compromete al futuro turístico; nadie quiere ver un bosque socarrado y menos estar expuesto a morir cercado por un fuego que

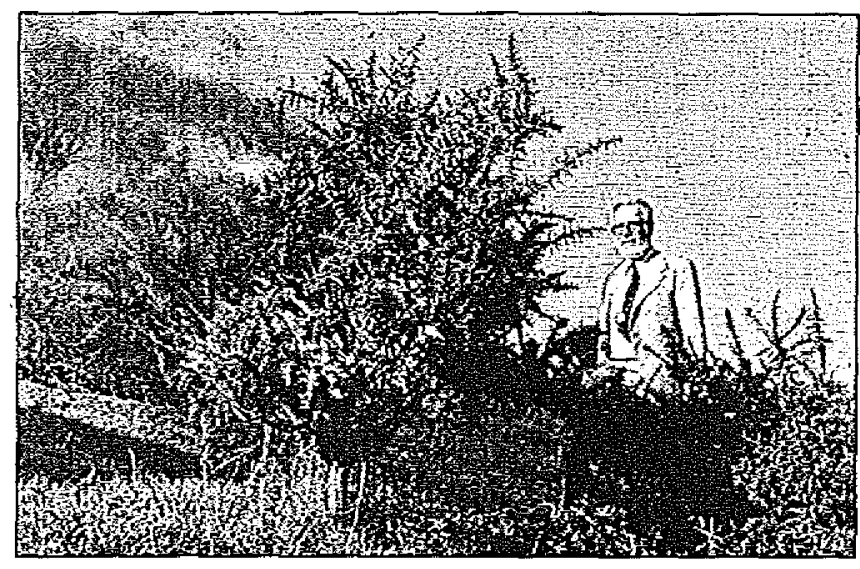

Incendio controlado. Escajo (Ulox europaeus) Mte. El Suelves (Asturias). 22-XIl-1978 (Folo: F. Fillat)

corre por el viento impetuoso. Conviene tener bosques pero con el pasto cortafuegos y no dejar sin pastar la hierba que se produce cada primavera. El incendio actual es fruto del abandono, de la "dejación colectiva" creyendo que se conserva sólo el monte. Los desbroces no son rentables ahora pero "se gasta mucho más" en aparatos y la gestión contraincendios "a posteriori".

Las plantas en el orden natural- producen para nutrir a los animales y forman conjuntos (céspedes) que no toleran el calor nocturno ni la fatta de agua; en mayojunio quedan secas y son como yesca para el incendio. El boj con la coscoja y corteza de pino queman mal, pero la hojarasca seca si lo hace con rapidez ardiendo pronto las ramas bajas y secas del pino en repoblaciones que no han sido "limpiadas" por falta de operarios. La entrada de obreros extranjeros aumentará el problema social dentro unos años y a mìt entender solo queda una solución: hacer que "trabajen los animales", pero para conseguirlo conviene dirigirlos bien. Tenemos dos caminos complementarios: a) usar el instinto animal y b) crear nuevas culturas agropecuarias.

\section{a) INSTINTO ANIMAL}

El caballo en monte Oroel terminó con los incendios tan frecuentes, pero además ahora contribuye pagando algo al Municipio de Jaca y a la Confederación Hidrogrática del Ebro propietaria de la repoblación en Pardina de Ordolés; su acción "limpiadora" aumentaría con vacas en abril-mayo seguidas de un rebaño en mayo-junio, antes de subir a puerto, pero es dificil organizarlo todo sin tener una propiedad comunal gestora y experimentada. Hace pocos lustros que hay caballos todo el año que, por instinto, recorren los cortafuegos de la repoblación y frenan el desarrollo excesivo de aliagas con erizón en los ambientes despejados.

El instinto animal jugó antes y aún jugará un enorme papel al gestionar los pastos pirenaicos; así se alivia el trabajo del pastor que debe "cuidar" mucho la direc- 
ción. Apenas se inicia la selección de animales "por comportamiento" y descuidamos los gufa del rebaño que antes eran elegidos con sumo cuidado, hasta diversificar las esquilas, con el "truco" para el gufa y la gestión correcta.

\section{b) LA SARDA Y SU IMPORTANCIA CULTURAL}

Creo que nuestras sardas manifiestan la cultura de nuestros abuelos que "se organizaron" a la perfección, manejando cabras y ovejas en montes de los Somontanos, Cinco Villas y Litera, con la coscoja recomida en media bola, como aún pude fotografiarla en Camporrells (Flora, vol. 60 Enciclopedia Temática de Aragón, pág. 238) y comento ahora. El uso de la sarda es antiquísimo (siglos, acaso milenios) y el "ganado de los. pobres" era manejado por cabreros experimentados con vocación de servicio; todo eso es un valor cultural autóctono perdido que apenas lamentamos, pero está en la raiz del probiema incendiario que ahora preocupa y nos amenaza. Cada media bola de coscoja -también llamada "sarda" (Quercus coccifera) en Aragón- era recomida por las cabras que apuraban el brote joven y asi la mantenían baja, sin superar la talla de medio metro y uno de diámetro basal. Poco combustible y además el pasto recomido por ovejas que subían al Pirineo en verano, impedía el incendio catastrófico. Cada mata de sarda forma media bola y produce rocío, una mojadura matutina "chupada" por el pasto periférico; cuando hay tormenta, la sarda filtra escorrentías que así no abarrancan y bajo su protección proliferan larvas destructoras de hojarasca, "el peligro" de incendio. Los burros, mulas y yeguas -cuando no tenían trabajo- completaban la limpieza del monte realizada por nuestros abuelos. Asi, la sarda daba cobijo a una diversidad animal extraordinaria y además al hombre rural que ha sido maltratado "en exceso" por nuestra civilización aculturante.

\section{LEÑADORES Y CARBONEROS}

La evolución de nuestras costumbres ha sido rápida y el monte carboneado dejó de serlo; aún recuerdo los alfares, tahonas y fábricas de ladrillo que "consumian" la maleza de nuestros montes; ya no se usa ceniza de las tahonas para la colada semanal. Las aliagas se apoderan del campo abandonado y pueden incendiar el bosque natural menos combustible. Falla el consumo de leñas y pastos, por lo que aumenta el peligro de incendio; así, el fuego consume lo que no aprovecharon animales y hombres. En relación con el uso de leñas, es probable que se pueda reanudar su empleo para obtener la llamada "bioenergía", para dar electricidad o calentar el agua de cada pardina o pueblo rural. Es más viable eso que la quema de unos "cardos" -la llamada biomasa- en "proyectos de cultivo carísimos y además paliaría el riesgo comentado. Sin embargo, os aseguro que no basta y necesitamos una organización similar o equivalente a la dula clásica de nuestros antepasados, es decir, urge muchísimo el saber organizar nuestras comunidades rurales tan abandonadas que ahora languidecen sin la escuela teóricopráctica ni empresas rurales, su modelo gestor.

\section{HAY PELIGRO EN NUESTRA JACETANIA}

Las sardas de Agüero ya forman ahora unos bos-

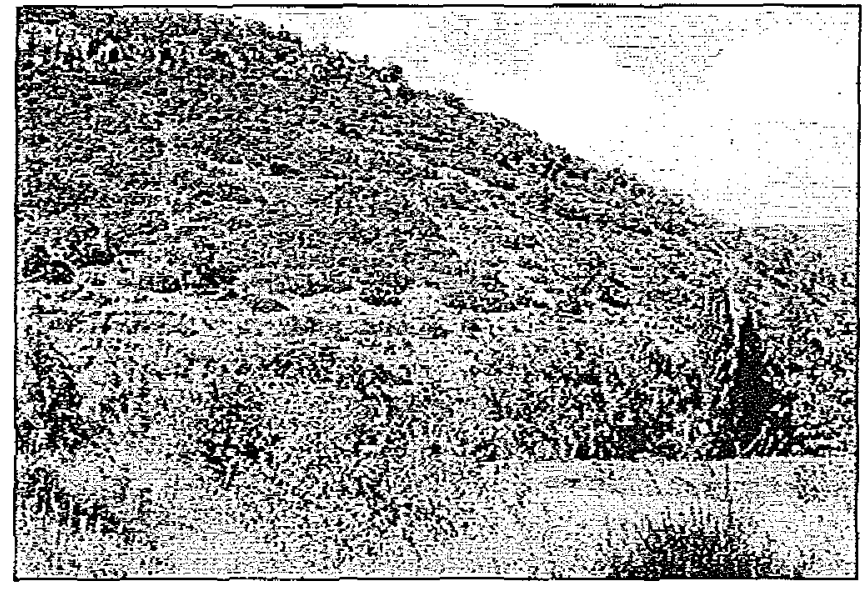

Sarda (Quercus coccifera). Foto del autor

quetes con talla de dos o más metros; alegran la vista junto a sus Mallos, pero pueden ser muy peligrosas si el incendio coincide con un viento impetuoso del Norte. Los montes vecinos han sufrido un incendio ahora y puede llegar también a ese rincón tan amable de nuestra comarca somontana. Sería un Jugar apropiado para preparas con antelación suficiente- unos desbroces muy ordenados, lentos, y además para "educar" al cabrero eficaz que -con sus cabras- completaría la limpieza, dejando así unos bosquetes bellos de sarda con carrascas y el pasto intercalado muy apurado.

El proyecto debería ser lento, para dar tiempo al encespedado natural (el rebaño hace "su pasto") entre las matas y bosquetes. Como véis no es para grandes inversiones ni unos "proyectos" realizados por técnicos foráneos, los de la maquinaria pesada que hinchan el presupuesto y "labran" montes destruyendo el suelo natural. Será una obra "de artesanía" y debe ser realizada en relación con la escuela interactiva (una EFA-Escuela Familiar Agraria) que forme «sobre la marcha" y muy bien al gestor agropecuario; además resulta esencial la Empresa (S.L.) cooperativa, en la que deben participar -además del Ayuntamiento-y con una acción por lo menos, "todos" los vecinos que "desean" evitar el incendio y así fomentar una gestión modernizada de la ganadería en sus montes, pero también de los campos con almeridros.

\section{OTEANDO EL FUTURO}

Dejadme soñar lo que podría ser realidad, hasta superar lo insinuado ahora, si el joven de Agüero toma conciencia de su responsabilidad y es "empujado" por su madre. Como especialista en clinámica del paisaje, dejadme perfilar algo de lo que podría ser superado en menos de dos lustros. En Agüero y Somontano de Ayerbe-Huesca hay muchos campos de almendro "infrautilizados" por falta de ovejas; se ha proyectado una escuela de pastores, pero el horizonte debe ser ampliado, para formar -en la EFA comarcal- al futuro gestor agropecuario. Seamos ambiciosos porque nuestro mundo rural to merece y debemos exigir que se cuiden más las raices de nuestra nacionalidad aragonesa. Las subvenciones "para no morir" (caridades) son destructoras; en cambio la Escuela y Empresas tipo modélicas son esenciales para formar al joven que debe prosperar en su pueblo y potenciar así los recursos que recibieron de sus abuelos. 